\title{
U.S. Geological Survey and Microsoft Cooperative Research and Development Agreement: Geospatial Data Browsing and Retrieval Site on the World Wide Web
}

\section{Introduction}

In May 1997, the U.S. Geological Survey (USGS) and the Microsoft Corporation of Redmond, Wash., entered into a cooperative research and development agreement (CRADA) to make vast amounts of geospatial data available to the general public through the Internet. The CRADA is a 36-month joint effort to develop a general, public-oriented browsing and retrieval site for geospatial data on the Internet. Specifically, Microsoft plans to (1) modify a large volume of USGS geospatial data so the images can be displayed quickly and easily over the Internet, (2) implement an easy-to-use interface for low-speed connections, and (3) develop an Internet Web site capable of servicing millions of users per day.

\section{Major Milestone}

The Microsoft TerraServer Web site (www.terraserver.microsoft.com) opened to the public in June 1998 serving more than 1 terabyte $(1,000,000,000,000$ bytes) of geospatial data from a userfriendly interface. TerraServer is a mutually beneficial research effort where the Federal Government and private industry have come together to provide the general public access to USGS geospatial data while allowing Microsoft and its partners to promote their data base systems that can scale to very large sizes.

Initially the CRADA focused on storing and displaying more than 3 terabytes of USGS digital orthophoto quadrangle (DOQ) images. A DOQ is a digital image

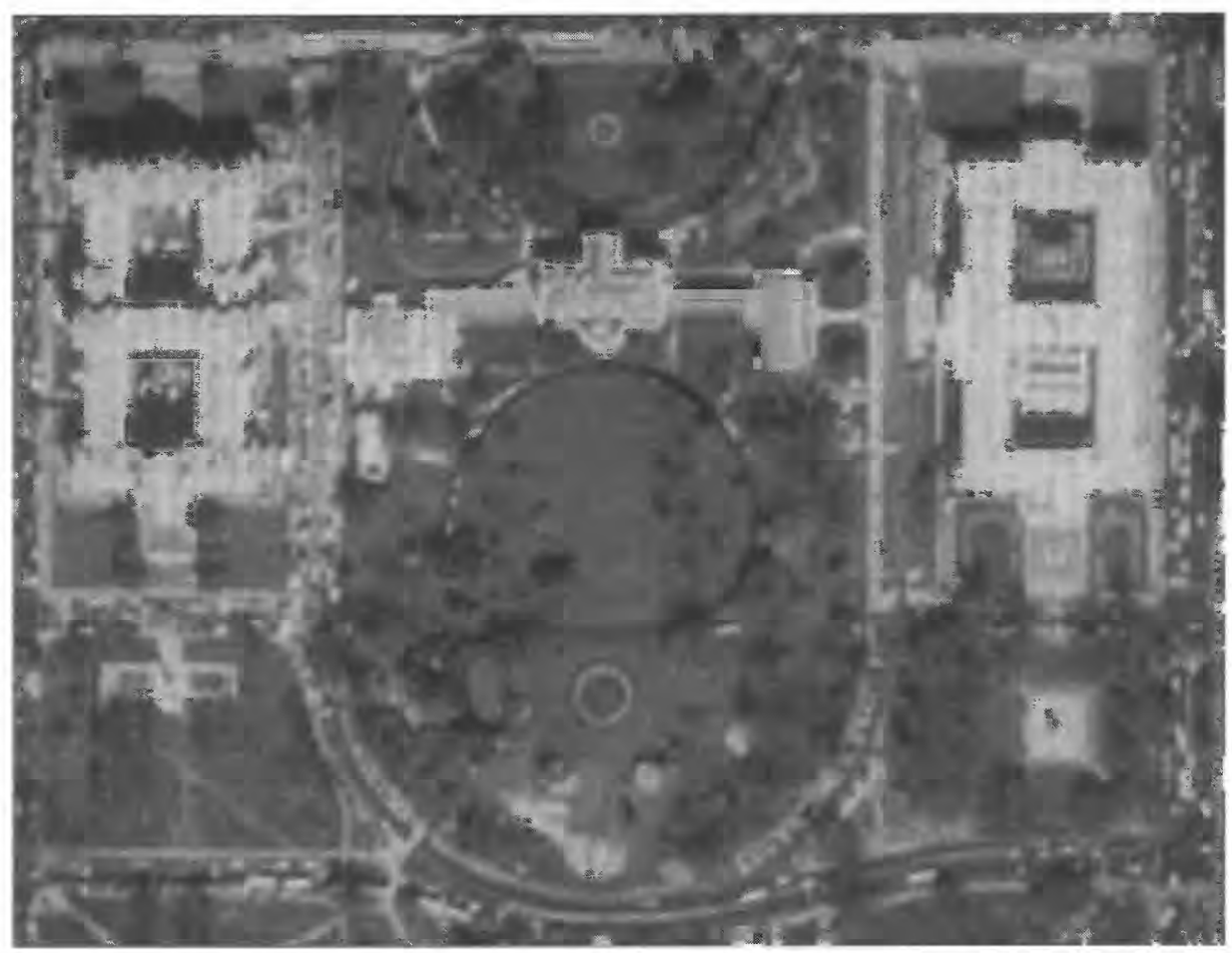

A portion of a USGS digital orthophoto quadrangle showing the White House in Washington, DC.

of an aerial photograph with distortions caused by the shape of the ground surface and camera angle removed. A DOQ combines the details of a photograph with the geometric qualities of a map.

Microsoft has made millions of resampled, compressed, browsable images of the entire USGS DOQ archive available on the Internet and is serving these online as JPEG image files for a testing period of at least 18 months. After viewing the resampled images on the Internet site, users are able to download the image they see to their own computer. With the user's permission, a Java software program will write the image to a file on the user's computer hard disk at no charge. Those wishing to purchase full-resolution, uncompressed DOQ images will be linked to the USGS Web site. Building on user feedback, Microsoft and the USGS will continue to improve the Internet site.

\section{Benefits of the CRADA}

This joint research effort increases the visibility of USGS geospatial data with the general public because these images are prominently displayed on the Microsoft Internet site, which already receives millions of inquiries per day. This is an opportunity for the USGS to inform new user communities about USGS geospatial data. 
Microsoft and its partners have extensive data display and storage technologies for handling terabytes of information on the Internet. The TerraServer Web site will show information technology managers that by using off-the-shelf software products from Microsoft and Web server storage solutions from its partners, they can easily manage and serve huge data bases on Internet sites.

\section{Future Plans}

The TerraServer site will be updated frequently as more USGS DOQ's are produced. Plans call for having 50 percent of the DOQ's for the conterminous United States online by the summer of 1999. There are also plans to add USGS digital raster graphics to the TerraServer at the same time.

After launching the initial display of resampled DOQ images on the Internet, the USGS and Microsoft will pursue additional research activities under the CRADA. The TerraServer Web site may be augmented with other USGS digital data products, such as digital line graphs, digital elevation models, and aerial or satellite images. In addition, linking other types of USGS data will be considered.

\section{Information}

For more information on this CRADA with Microsoft, contact:

Beth Duff

U.S. Geological Survey

508 National Center

Reston, VA 20192

Phone: 703-648-4621

Fax: 703-648-5939

E-mail: bduff@usgs.gov

More information about DOQ's can be found at:

mapping.usgs.gov/mac/isb/pubs/factsheet s/fs 12996.html

For further information on CRADA opportunities with the USGS National Mapping Division, please contact:

Ernest B. Brunson

U.S. Geological Survey

500 National Center

Reston, VA 20192

Phone: 703-648-4643

Fax: 703-648-5542

E-mail: ebrunson@usgs.gov

\section{Additional Information}

For information on other USGS products and services, call 1-888-ASK-USGS, use the EARTHFAX fax-on-demand system, which is available 24 hours a day at 703-648-4888, or visit the general interest publications Web site at mapping.usgs.gov/www/products/ mappubs.html.

Please visit the USGS home page at www.usgs.gov/. 